\title{
OFRENDAS ATACAMEÑAS EN LA COLECCIÓN DE MONSEÑOR CAMPAGNER (TREVISO, ITALIA)
}

\author{
Laura Laurencich-Minelli ${ }^{1}$
}

\section{* Introducción: La colección de Monseñor CAMPAgNER}

\section{Resumen}

Se discute la ergología y la iconografía de una selección de 16 piezas de las 72 procedentes de San Pedro de Atacama (Chile) publicadas recientemente en Italia en un catálogo de la Colección Campagner. Cada objeto ha sido realizado en un solo trozo de madera, y con ellos los antiguos atacameños realizaban un ritual chamánico. Se discute la ideología que podía estar en la base del poder político y religioso de San Pedro de Atacama, así como la posibilidad de que el espacio inicial incaico fuese aquel correspondiente a Tiwanaku, tal como sugieren algunas piezas descritas en este artículo.

Palabras claves: Angelo Campagner - Gustavo Le Paige - parafernalia inhalatoria - iconografía - colección arqueológica - Atacama - Tiwanaku.

This article describe 16 objects of the 72 items from San Pedro de Atacama (Chile) in the Campagner Collection. Each object was carved out of a single wood piece and with them the atacameños officiated shamanic rituals. Here, we also discuss the ideology which might be at the basis of the Atacama political-religious power, by showing how some of the Campagner's items support the archaeological suggestion that the initial incaic could be related to Tiwanaku.

Key words: Angelo Campagner - Gustavo Le Paige - snuffing paraphernalia - iconography - archaeological collection - Atacama - Tiwanaku.

Recibido: junio 2010. Aceptado: febrero 2011.
En el ámbito de la investigación Corpus Antiquitatum Americanensium -que desde 1984 tengo el honor de dirigir en Italia para la International Academic Union (UIA), Bruselas-, encontré en 1989 la colección precolombina que Mons. Angelo Campagner (1916-1993) reunió durante su estancia en Chile (1949-65). ${ }^{2}$ Se trata de unas 5.000 piezas procedentes de Ecuador, Perú, Bolivia, Chile y Argentina. La parte más consistente de la colección es la chilena y, en este ámbito, la más significativa es la que procede de la región de Atacama: la única que Mons. Campagner excavó, en parte directamente, y en parte adquirida o recibida como donación. Pude conocer personalmente a Mons. Campagner que en aquel entonces (1989) estaba montando la exposición definitiva de su colección en el Museo del Seminario de Treviso que abrió en 1993, es decir, poco antes de su fallecimiento. Mons. Campagner me enseñó parte de su correspondencia y me contó acerca de las interesantes discusiones científicas, indicaciones bibliográficas e intercambio de objetos que tuvo con personajes de su época. Escuchándolo, como en una película "veía" a ciertos personajes que yo había conocido en la época de mis estudios universitarios a través de los libros: para Bolivia, a los arqueólogos Carlos Ponce, Arthur Posnasky y al director del Museo Arqueológico y Ecológico del Colegio Mayor de los Jesuitas (hoy Museo Nacional de Etnología y

\footnotetext{
${ }^{1}$ Dipartimento di Paleografia e Medievistica, Piazza S. Giovanni in Monte nº 2, Boloña - 40124, ITALIA. Email: laura.laurencich@unibo.it

2 Monseñor Angelo Campagner nació en Santa Elena de Silea (Treviso) el 16 de septiembre de 1916. El 26 de mayo de 1940 es ordenado sacerdote. A fines de 1948 viaja a Chile donde, en 1949, es nombrado párroco de la parroquia de San Rafael de Chacance, Oficina de María Elena. Posteriormente, en 1954 es nombrado párroco de la catedral San José de Antofagasta y docente de disciplinas humanísticas en el Seminario. En 1955 es vicario foráneo de la ciudad y en 1961 es provicario general de la diócesis. En 1969 su salud delicada lo obliga a regresar a Treviso donde dirige, ordena y reconstruye el patrimonio de la Biblioteca del Archivo Capitular de Treviso, destruida en 1944, hasta su muerte el 19 de noviembre de 1993.
} 
Folklore); para las relaciones entre el altiplano boliviano y Chile, al arqueólogo Dick Ibarra Grasso; para Perú a la arqueóloga Rebeca Carrión Cachot. Además, en Chile Mons. Campagner contó con la amistad y el apoyo de los directores del Museo Arqueológico de La Serena: Antonio Serrano y Jorge Iribarren Charlin y, al final de su estancia en el país, trabó también amistad con el director del Museo Arqueológico de Calama, Lautaro Núñez, quien, según Mons. Campagner, lo convidó a participar en excavaciones cerca de Calama. También, entre los personajes conocidos por Mons. Campagner en Chile se encuentra el Padre Gustavo Le Paige. De este último, Mons. sabía muchas anécdotas porque lo había conocido cuando, recién trasladado desde el Congo Belga a la parroquia de Chuquicamata y luego a la parroquia de San Pedro de Atacama, lo guió por los sitios arqueológicos de la región. Sin embargo, Mons. Campagner, conocía la zona desde hacía tiempo, lo suficiente como para acompañar al Padre Le Paige en las investigaciones iniciales y sugerirle los mejores sitios en los que trabajar (Le Paige 1964). De esta manera, las investigaciones iniciales del Padre Le Paige fueron realizadas conjuntamente con Mons. Campagner.

Al examinar el archivo de Mons. Campagner me di cuenta de que su trabajo arqueológico, a pesar de no tener en cuenta el método estratigráfico, ${ }^{3}$ sigue una cierta metodología empleada en los años 50 para excavar los cementerios precolombinos. Es decir, establece la cultura según el tipo de tumba excavada y los estilos de los objetos hallados después de haber apuntado el contexto detallado de una tumba y, en un borrador de mapa, el sitio; además, fue siempre muy exacto a la hora de anotar, incluso en el caso de los objetos que había recibido como donación, no solo el donante sino también el sitio que aquel le había declarado como procedencia y su pertenencia a una tumba con su eventual descripción. En suma podemos asegurar que él, junto al Padre Le Paige, sentó las bases rudimentarias de la arqueología funeraria en Atacama. Lamento haber dejado el examen exhaustivo de su archivo para cuando se publicara el catálogo de su colección,

\footnotetext{
3 El método estratigráfico fue introducido por Max Uhle en Chile entre 1919-22 en el sitio de Punta Pichalo, pero no suscitó mayor interés fuera de los círculos de los especialistas. Sin duda, Mons. Campagner no estaba al tanto de los trabajos de Uhle porque he podido comprobar que ni su biblioteca ni su archivo contienen obras o menciones sobre el estudioso alemán.
}

porque, desafortunadamente, el fallecimiento de Mons. Campagner en 1993 separó el archivo de la colección. Esperemos que el Museo del Seminario logre adquirirlo antes de su dispersión y abrirlo al público. Volviendo a la colección, en los años 50, Mons. Campagner, con el fin de introducir a los alumnos de las escuelas secundarias a las civilizaciones de América precolombina, fue enviando poco a poco a Treviso lo que estaba coleccionando en Sudamérica, y que su hermano Antonio, aficionado de la prehistoria del Véneto, expondría en las escuelas y documentaría por primera vez, concretamente, en la revista Treviso Nostra (1964).

En los años 80, Mons. Campagner donó su colección al Museo del Seminario de Treviso (donde se conservan otras interesantes colecciones ya sea arqueológicas italianas o etnográficas de varias partes del mundo) y escribió luego el inventario "ragionato": "Archeologia e Paletnografia precolombina del Sud America. La raccolta nel Seminario di Treviso" $(1993) .^{4}$

En este artículo, presento una selección de 16 piezas de las 72 procedentes de Atacama recientemente publicadas (Laurencich-Minelli y Colella 2008) con el deseo no solo de dar a conocer la existencia de la Colección Campagner y activar investigaciones complementarias entre los estudiosos italianos y chilenos, sino también de aportar evidencias acerca de cómo en los Andes unen y unían de manera específica a la región atacameña con el Altiplano Circumtiticaca. De hecho, por un lado tenemos la región atacameña con su riqueza en cobre y piedras semipreciosas trabajadas por sus habitantes de manera refinada, y sus oasis y río Loa que facilitaban también la vía hacia el Pacífico; por otro lado, tenemos el lago Titicaca, donde tenía su centro político el Estado Tiwanaku. A pesar de la complementariedad geográfica de estas regiones, apenas alrededor de 600 DC se hallan objetos que documentan claramente un fuerte intercambio cultural entre estas

\footnotetext{
4 Mons. Campagner (1993) en su inventario ragionato documenta 655 números que comprenden 5000 piezas porque agrupa las puntas de proyectil, que constituyen $2 / 3$ de la colección, según el material, el sitio de procedencia y las técnicas de trabajo, dando a cada grupo un único número de inventario. En cambio, numera y describe una tras otra las demás piezas después de haberlas clasificado por culturas y regiones subdividiéndolas en madera, cerámica y textiles: piezas que proceden no solo de Chile sino también, aunque en número menor, de Bolivia, Argentina y Ecuador.
} 
dos regiones, cuando las redes de interacción Tiwanaku están ampliadas al máximo. Pero nosotros sabemos que no solo tenemos que ser muy precavidos a la hora de detectar las influencias externas para culturas cuya fuente es solamente arqueológica, sino también que tales culturas, antes de legar claras huellas arqueológicas de sus contactos, tuvieron muchos intercambios culturales que pueden haber dejado escasa documentación arqueológica. De todos modos, según se desprende de los estudios arqueológicos, es alrededor del s. VII que Tiwanaku alcanza plenamente a Atacama, donde los señores de los principales oasis se aliaban de manera significativa con los representantes de Tiwanaku. ${ }^{5}$

Con la muestra de la Colección Campagner, objeto de este artículo, al igual que con el catálogo recién publicado (Laurencich-Minelli y Colella 2008), intentamos actualizar la clasificación de Mons. Campagner, que se remonta a los años 60 , con un bosquejo cronológico basado ya sea en los apuntes que él había sacado de sus principales datos de campo, o en los análisis estilísticos y de las técnicas de trabajo que se han efectuado para cada pieza: bosquejo que a su vez se ha centrado en la cronología de la región atacameña (Tarragó 1968, 1989; Berenguer et al. 1986,1988$)$ para apoyar este primer intento clasificatorio de una colección recogida sin referencias estratigráficas. ${ }^{6}$ Sin embargo, este artículo es un intento preliminar

5 Para el bosquejo arqueológico de las relaciones entre Atacama, Mons. Campagner (993) refiere que su colección atacameña procede de Toconce y Cupo en la región del Loa Superior, de Catarpe, es decir unos $10 \mathrm{~km}$ al norte del centro del actual pueblo de San Pedro, del callejón Larache en San Pedro y de sitios de los ayllu de Solor, Cucuter, Beter, Poconche y Coyo, que conforman los oasis de San Pedro de Atacama.

6 La cronología para la cuenca de Atacama considera las fases Sequitor (100-400 DC), Quitor (400-700 DC), Coyo (700-900 DC) mientras que la fase Solor corresponde al período Intermedio Tardío, y la fase Catarpe al momento de influencia incaica (Tarragó 1989). La cronología propuesta por Mons. Campagner atribuye las piezas del Desierto de Atacama a la cultura atacameña (pero sin ofrecer ninguna base cronológica) e inca, mientras que adscribe las piezas que proceden de Bolivia -que no se presentan en este artículo sino solamente en Laurencich-Minelli y Colella (2008) y que él utiliza con una finalidad comparativaa las culturas Tiwanaku, Inca y a la época de Conquista. Mons. Campagner sigue un enfoque cronológico sui generis para Atacama que parece ser el resultado de la reinterpretación sin fechas del de Uhle (1922), es decir que la cultura que Campagner llama "atacameña" iría de 600 a 1350 DC, mientras que para el alti- para fomentar el intercambio de datos con el fin de que se empiece a profundizar el interesante cuadro precolombino atacameño que brinda esta colección y ampliarlo con otras colecciones.

\section{* Objetos de uso chamánico}

El pequeño conjunto de 16 objetos de madera de la Colección Campagner que aquí presento, proporciona una muestra de las ofrendas para realizar rituales chamánicos durante el período Formativo Tardío y el período Medio, es decir, entre los años 100 y 900 DC (Laurencich-Minelli y Colella 2008). Las piezas que forman este pequeño conjunto serían anteriores y contemporáneas a las relaciones de Tiwanaku con san Pedro de Atacama? La muestra que tratamos en este artículo cuenta con tres vasijas miniaturas, dos figuritas humanas, seis tabletas, dos cucharas, tres tubitos; remito al catálogo para las fichas descriptivas de este material y de las demás piezas de la colección. ${ }^{8}$ En esta ocasión quisiera poner de relieve

plano boliviano parece utilizar la cronología de Ponce (1972) y Posnansky (1945). A mi parecer, todas las piezas de Atacama de Mons. Campagner se puedan adscribir a fines del período Formativo y principalmente al período Medio (100-900 DC).

7 Dado que los objetos pertenecientes a la parafernalia atacameña utilizados con fines chamánicos serían más antiguos que la influencia de Tiwanaku en Atacama y que ésta se documenta claramente a partir del s. VII, la muestra utilizada en este artículo parece corresponder a las fases Quitor (400-700 DC) y Coyo (700-900 DC) (Torres 2004).

8 En este artículo, mantengo los números de las piezas que presentan el catálogo (Laurencich-Minelli y Colella 2008) para poder facilitar la lectura oportuna de cada ficha. Las tres vasijas miniaturas corresponden a los siguientes números del catálogo (entre paréntesis pongo también los números de inventario y añado las procedencias): $n^{\circ}{ }_{1}$ ( $n^{\circ}$ inv. 379), n $n^{\circ} 2$ (380), n 72 (397) proceden de Catarpe (San Pedro de Atacama); las seis tabletas corresponden a los n’s catálogo 36 (349) denominado Dignatario procede de San Pedro de Atacama; 40 (353), mujer, procede de Catarpe; 42 (355) denominado Yaya Mama; 43 (356) denominado Gran Sacerdote; 41 (354) llamado de los dos pumas; 38 (351) (Catarpe) llamado del Águila: estas cuatro tabletas $(38,41,42,43)$ proceden de Catarpe; las dos cucharas, 7 (415) y 8 (416) denominadas de los dignatarios, proceden de Catarpe; los tres tubitos con los n's 56 (402), 57 (403) y 59 (405) conocidos como de los tres de dignatarios con hacha y cabeza trofeo proceden de Catarpe; una figurita humana ( 75 [366]) procede de Catarpe y la otra (76 [365]) también de Catarpe. 
el potencial iconográfico y ergológico que contienen las ofrendas atacameñas de la Colección Campagner, a pesar de la falta de datos estratigráficos, pues brinda dos curiosos elementos comunes a todas sus piezas a lo largo de las fechas consideradas: 1) las finas decoraciones realizadas, ya sea de bulto, ya sea en bajorrelieve con o sin detalles engastados de turquesas; 2) el hecho que cada objeto se ha sacado, con muchísimo costo y habilidad manual, de una pieza única de madera muy dura.

Hay que subrayar que la ergología de los nativos americanos plantea que el tipo de material utilizado, al igual que las técnicas de trabajo empleadas para realizar un objeto, reflejan no solo la ideología de las culturas que lo produjeron, sino también que el objetivo principal de la ergología de los nativos es el de la expresión simbólica contenida en la decoración y en los materiales utilizados. Por lo tanto, del primer punto resultaría que las ofrendas recogidas por Mons. Campagner pertenecían a individuos especiales que tenían maneras distintas de expresarse en el tiempo y/o en el espacio, como evidencia también el estilo de sus tocados (Oakland 1992); es decir, ellos formarían parte de grupos que tenían cada uno sus tradiciones pero que, según el segundo punto, habrían compartido una ideología, como indica el hecho que los objetos compartidos se trabajaron en una sola pieza. ${ }^{9}$

Veamos, pues, si la lectura del simbolismo de los materiales escogidos para el trabajo nos ayuda a aclarar algunos aspectos de estos datos nebulosos sobre la ideología monolítica a la luz también de una fuente de la época de los incas coloniales, que aporta detalles interesantes sobre el tema (Valera 2007 [1618]). Valga como ejemplo que en el mundo inca, de acuerdo a este cronista, la madera dura significaría la sabiduría sobrehumana, al parecer propia de apenas unos destacados amautas, mientras que la roca dura (ígnea) representaría la raíz del mundo. Dado que la visión y la percepción del ambiente andino parecen remontarse a tiempos muy remotos (Burger 1993; Bauer 1996), considero que se puede correr el riesgo de atribuir estos datos también a tradiciones preincaicas como las

9 Para el significado de la ergología de los nativos americanos, ver: Desveaux (2001), Frame (1986, 2004), Laurencich-Minelli y Rossi (2007). Al tratarse del tipo de tocado llevado por los señores, el elemento más notorio para evidenciar un rango y/o una cultura, lo tomo como elemento discriminante (Oakland 1992). fases Sequitor, Quitor y Coyo del período Medio del Salar de Atacama. En síntesis, al leer los puntos 1 y 2 sobre el potencial iconográfico, ergológico y material, y analizados desde la perspectiva que nos brinda la arqueología, resulta que los objetos de la Colección Campagner de los momentos que nos interesan, expresarían el prestigio de los "señores" de Atacama, durante épocas y/o asentamientos distintos: su prestigio alcanzaba ribetes sobrehumanos (es decir, semidivinos como la madera), su territorialidad no era fija, sino transferible de un lugar al otro (al igual que una pieza de madera), tal vez por no estar vinculada al linaje sino a las capacidades "sobrehumanas", es decir chamánicas, de cada uno - como todavía hoy en día la nobleza chamánica de los Cabecar..$^{10}$ Los señores de Atacama relacionados con Tiwanaku estaban unidos por el poder centralizado en el altiplano del Titicaca (como indica la iconografía de buena parte de la colección que recuerdan la del lago y, de manera específica, la de la Puerta del Sol). En la litoescultura del altiplano central como, por ejemplo la Puerta del Sol, durante los momentos de la cultura San Pedro (Bittmann et al. 1978), se encontraría la raíz del mundo cuya fuerza simbólica unificaría a los señores de Atacama.

A pesar de no saber como definir este poder que parece ser político y religioso al mismo tiempo, concuerdo con Meyers (2002), respecto de que no podemos evaluarlo con los parámetros con los que estudiamos a los antiguos imperios del Viejo Mundo, que buscaban el control político directo o indirecto de un territorio, porque el Nuevo Mundo seguía una lógica de valores distinta a la nuestra, como hemos visto mediante la ergología, lógica que se está empezando a vislumbrar. Una lógica que llamo holística por abarcar y transformar, como en un juego de espejos, un ser que se transforma y se multiplica en dos, cuatro, etc. seres, siguiendo la geometría cósmica, para luego transformarse de nuevo en un ser único que los engloba a todos. Las culturas que esta lógica produjo son incomprensibles para nosotros, si las examinamos

\footnotetext{
${ }^{10}$ En los años 70, cuando estuve trabajando con los chamanes Bribri y Cabecar de Costa Rica, el poder del chamán no se transmitía por linaje sino por el grado de capacidad chamánica que se tenía; capacidad que quedaba declarada durante el "encuentro" del jaguar en la selva (es decir, era el jaguar quien escogía al futuro chamán) a lo que seguía la escuela chamánica que era la que definitivamente permitía al chamán entrar en el círculo chamánico (Laurencich-Minelli 1978: 131-135; Bozzoli 1982 Ms: 14-40).
} 
con nuestra lógica lineal, inductiva y deductiva, porque el pensamiento que está en la base del mundo de los nativos actúa según un proceso amebiforme y transformista que amplía y/o reduce sus elementos, considerados todos animados y que pueden sumarse en un unicum ampliado y aparentemente "monolítico", pero que es distinto a la suma de los elementos que lo componen. Lógica que explica, por ejemplo, las múltiples técnicas de aleación de los metales puesta en práctica en el mundo andino no tanto para construir armas cada vez más poderosas, o para economizar la presencia del oro, como ocurrió en el Mediterráneo antiguo, como para unir entre sí y de manera "monolítica" metales distintos, como son el oro, la plata, el cobre, puesto que cada uno representa elementos básicos en su mundo. "lógica que explica también los curiosos cálculos de los números sagrados incas y las maneras de sumarse entre sí de los seres divinos y de las fuerzas cósmicas bajo forma de números sagrados no solo en el ámbito acroandino, sino también mesoamericano, como se desprende en particular de su calendario ritual, el tonalpohualli, que apunta a la fusión de todos ellos en una divinidad amplia pero a su vez constantemente divisible entre el número dos: es decir lo masculino y lo femenino. ${ }^{12}$ Lógica que armoniza y privilegia la

${ }^{11}$ Para la lógica holística ver Desveaux (2001), Frame (1986, 2004), Laurencich-Minelli y Rossi (2007). De acuerdo con Valera (2007 [1618]) que escribe sobre el mundo incaico, el oro, la plata y el cobre representan respectivamente el Sol con la nobleza masculina, la Luna con la nobleza femenina así como la Tierra y el pueblo. Un ejemplo claro de esta lógica holística es el sistema de doradura y plateado, conocido como la mise en couleur, que permite construir piezas de cobre doradas y/o plateadas que hemos pensado, siguiendo nuestra lógica, que estuvieran realizadas para economizar el oro o la plata: valoración que es absurda en Perú prehispánico donde oro y plata abundaban, y que, en cambio, debe relacionarse con la necesidad de presentar unidos en una única pieza, dos o tres metales que al mismo tiempo estarían separados. Ver por ejemplo, el ticcisimi en cobre plateado: yupana anexo a Exsul Immeritus que con los metales que lo forman, presenta la Tierra en la parte interna y la Luna en el plateado externo.

12 Para los curiosos cálculos de los números sagrados andinos que llevan a la divinidad, ver Valera (2007 [1618]: cc.5v-10v, Add.II; Laurencich-Minelli 2004, 2007a, 2007b). Para el tonalpohualli mesoamericano que apunta a la fusión de todos los dioses en una divinidad, la de la creación de ese ciclo del mundo, que los incluye a todos en su realidad única pero constantemente divisible a partir del número dos: es decir lo masculino y lo femenino, ver López (1983: 75-87; Laura Laurencich-Minelli 2003a, 2003b). El tonalpohualli no solo conjuga los 20 dioses del calendario y los 13 sociedad como una totalidad y no como un conjunto de individuos, que lleva a vivir el mundo como poblado por una miríada de seres que al mismo tiempo forman una divinidad en los Andes (Valera 2007 [1618]). Lo curioso es que ya hace algún tiempo Valcárcel (1925, 1965 [1945]) y Carrión (1959) habían vislumbrado la existencia en el mundo andino de esta ideología que no había sido entendida por los misioneros por considerar todos esos razonamientos como idolatría, y que López (1997) había planteado también para Mesoamérica. ${ }^{13}$ Lógica que mira la sociedad como grupo y no como un conjunto de personas, que mira al mundo entero sin distinción entre lo terreno y lo sagrado pero que está poblado por seres que actúan como una compleja totalidad, lógica que apunta a dar fuerza al grupo y, entre el grupo, a la nobleza en detrimento del individuo como sujeto único. Lógica que ha producido un mundo, el de América indígena, que no podemos leer aplicándole las conceptualizaciones europeas que son básicas en nuestra lógica lineal que ha originado el pensamiento individualista con que tenemos la costumbre equivocada de mirar al mundo indígena, hasta el extremo de analizar las unidades políticas monolíticas andinas como si analizáramos el mundo mediterráneo y/o el Imperio romano. ${ }^{14}$

dioses - número que los acompañan con la geometría cósmica de los puntos cardinales-, sino que nos presenta dioses capaces de asumir las características de otros dioses y de sumarse entre sí a lo largo del pasar de los días, dando lugar a aquellos que, con nuestra lógica lineal, solemos llamar aspectos de una divinidad pero que en realidad son divinidades distintas en continúo cambio, según el proceder de los días, y al mismo tiempo partes del todo: el dios nunca visto y conocido.

${ }^{13}$ Es decir el dios nunca visto y nunca conocido de los mesoamericanos al que refiere el cronista Tezozomoc, al igual que la divinidad única de los andinos, no sería un invento de los indígenas coloniales para llevarse bien con los conquistadores y con los evangelizadores, sino que sería una concepción propiamente indígena (Valcárcel 1925, 1965 [1945]; López 1997).

${ }^{14}$ Lógica que formaba el sustrato de todo el mundo precolombino y que he constatado aún actualmente en las figuras lingüísticas de los actuales indios Guaymí del Área Intermedia (con quienes llevé a cabo un trabajo de campo) entre los cuales el sonido, la figura y el concepto están cambiando y sumándose entre sí sin parar pero no se pueden fijar y abstraer en nuestras letras del alfabeto; de ahí la dificultad de los niños hablantes de lenguas indígenas para aprender nuestra escritura alfabética con los medios didácticos de nuestras escuelas; lógica holística que considero que es una de las causas por las cuales los indios se consideraban, y se consideran también a menudo hoy, por quien no es indio, no cumplidores de 
En esta lógica enfocamos la ergología y la iconografía de los objetos pertenecientes a la parafernalia atacameña de la Colección Campagner para uso chamánico y las relaciones que, durante el período Medio, San Pedro de Atacama mantenía con el altiplano boliviano y, de manera específica con Tiwanaku: lógica que lleva a una especie de ideología unificada como base del mundo político y religioso atacameño. A la luz de lo que estamos empezando a entender de esta lógica, parece en cambio que lo que unía a los señores de Atacama con los representantes de Tiwanaku era esta suerte de ideología monolítica que, de acuerdo con la lógica holística, produjo una sociedad compuesta no por individuos sino por grupos que podían fundirse en una unidad política a pesar de estar subdivida y ser divisible a partir del número dos que representa por un lado la parte masculina, luminosa y alta (llamada hanan en el mundo andino), y por el otro, la femenina, oscura y húmeda (llamada hurin). Solamente en los Andes, parece haber alcanzado la unidad monolítica, es decir, lo que en la cultura europea se denomina un "Imperio" cuyo centro se hallaba, no casualmente, en el lago Titicaca, el lugar donde el simbolismo matérico sugiere que se encontraban las raíces del mundo y donde la arqueología y las fuentes etnohistóricas confirman que estaban las raíces del último mundo andino prehispánico, el de los incas (Ramos Gavilán 1988 [1621]; Cobo 1956 [1653]; Kolata 2004). Esta unidad no tiene nada que ver con nuestros imperios de la Antigüedad porque parece estar relacionada no tanto con juegos políticos y comerciales, sino más bien con los juegos dictados por la fuerza cós-

sus promesas, lógica holística que probablemente está relacionada con el proceso mental de las lenguas americanas que son aglutinantes, es decir que agrupan de modo que añadiendo infijos o sufijos a una palabra, ésta cambia de significado. Lógica que reconozco también en la lectura de los ciclos de la memoria andinos leídos a través del lenguaje textil actual de los aymara, a los que se refieren Arnold y Yapita (2000), que nos presentan a la sociedad andina tradicional como un ser vivo textil que es persona pero que al mismo tiempo es parte del todo, como los hilos son parte de la tela. Lógica que encuentro también en la logique transformationnelle que Desveaux (2001) nos presenta para los materiales etnográficos de América del Norte y en particular para los ojibwa, los iroqueses, los sioux, si bien extendiéndola también a América del Sur y que concedería a la mitología, a los rituales, a la sociología, incluso a los términos de parentela, una relación transformativa continua entre sí. Para mayores detalles sobre la lógica holística, ver Arnold y Yapita (2000: 273-430), Laurencich-Minelli (2007a, 2007b), Laurencich-Minelli y Rossi (2007). mica de un ambiente de grandes contrastes como el andino, que se consideraba contenedor de la raíz del mundo en su alto, hanan, y por una nobleza "semidivina", puesto que manejaba y equilibraba la fuerza que brotaba de esta raíz del mundo. Nobleza que enviaba posiblemente a sus representantes, no tanto por razones de poder y de riquezas como por razones de equilibrio cósmico, a las zonas donde ellos, portadores de lo "alto" hanan, podían alcanzar el ambiente del "bajo", hurin, contribuyendo a equilibrar el mundo (p.e., utilizando también elementos que podían añadirle "fuerza" y equilibrio al ambiente alto, hanan, del Titicaca, como las turquesas que, con su color parecen repetir el color del lago).

Ahora que ya hemos tenido en cuenta el simbolismo genérico que proporciona la ergología y la madera dura empleadas para construir los objetos de la parafernalia para el uso chamánico en Atacama, veamos que otros datos nos aportan los 16 objetos de madera de la Colección Campagner de Atacama que se discuten en este artículo. Empecemos por tres minúsculas vasijas cuya función parece ser la de pequeño mortero para pulverizar la Anadenanthera sp. u otro material relacionado con el uso chamánico (Wassén 1972): están trabajadas en una única pieza de madera dura ("quebracho", según Mons. Campagner 1993) que, de acuerdo a la Figura 1 ( $\mathrm{n}^{\circ}$ cat. 1) y a la Figura 2 ( $n^{\circ}$ cat. 2 ) en la parte externa, a bulto redondo, de manera que cada una de las dos vasijas se ve como un señor sentado con los brazos sobre el vientre cuyo gorro Tiwanaku forma la embocadura de la vasija misma, probablemente para subrayar que ese señor es el dueño del polvo allí guardado. La tercera minúscula vasija de la Figura 3 ( $n^{\circ}$ cat. 72 ), no presenta en cambio ninguna decoración externa pero el interior está cavado de manera que queda dividido en cuatro compartimientos cuadrados cuyas paredes son muy delgadas (máx. 0,2 $\mathrm{cm}$ ): un trabajo muy complejo y delicado, dado el tamaño total de la vasija $(6 \times 3 \times 5 \times 4 \mathrm{~cm})$, que se realizó en parte quemando, y en parte alisando la madera. De todos modos, esta división de la parte interna de la minúscula vasija la conecta con el número cuatro y con el cuadrado que además es la figura base de los cuatro compartimentos que tal vez contenían cuatro variedades distintas de polvo de uso chamánico y/o reproducían en miniatura la que podría ser la división básica del territorio. En este último caso, se trataría de un curioso anticipo de la división en cuatro que caracterizará el Tawantinsuyu, anticipo que 


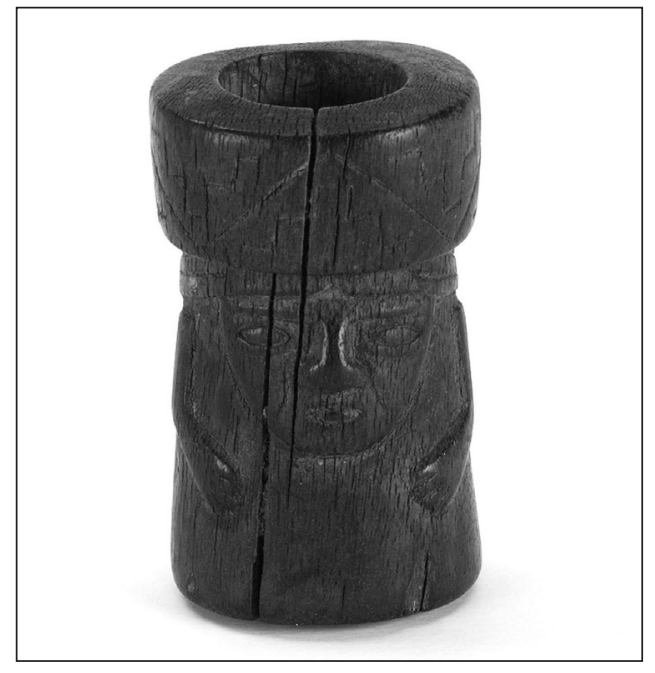

Figura 1. Pequeña vasija ( $n^{\circ}$ cat. 1).

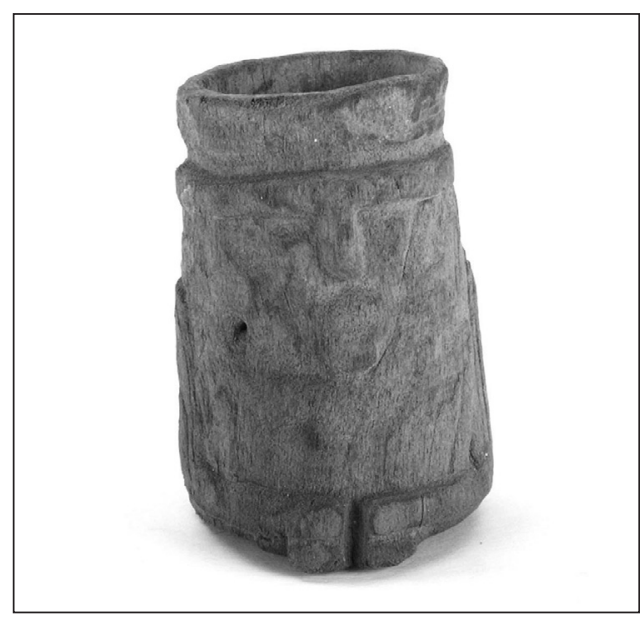

Figura 2. Pequeña vasija ( $n^{\circ}$ cat. 2).

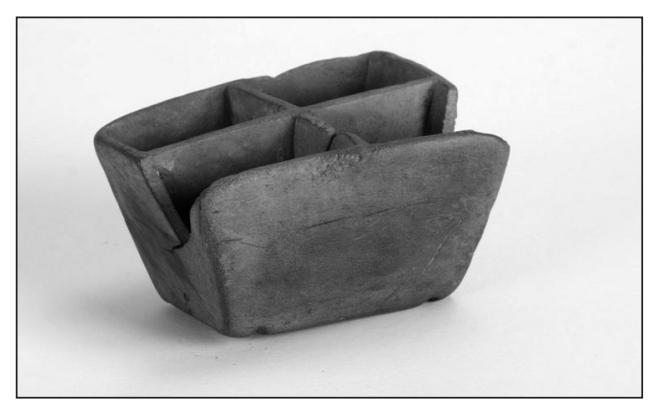

Figura 3. Pequeña vasija ( $n^{\circ}$ cat. 72$)$.

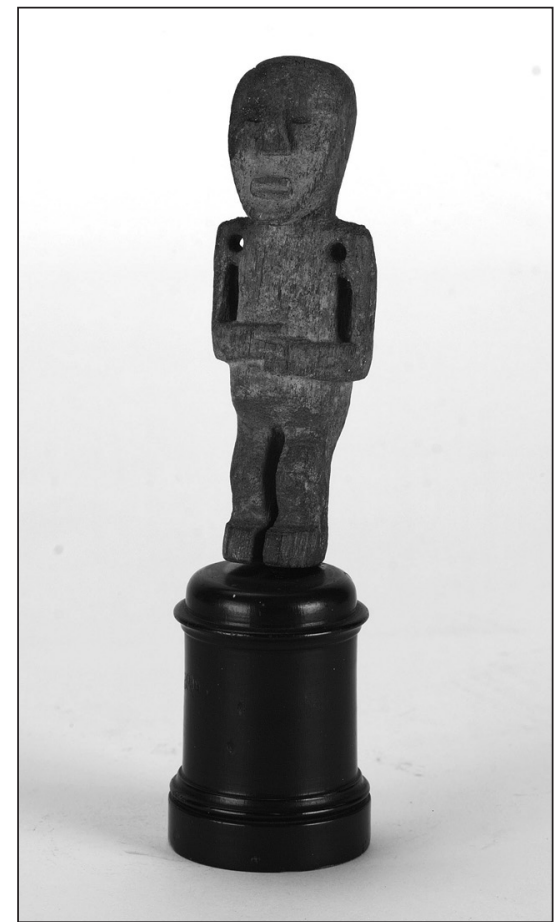

Figura 4. Figurilla masculina parada ( ${ }^{\circ}$ cat. 75$)$.

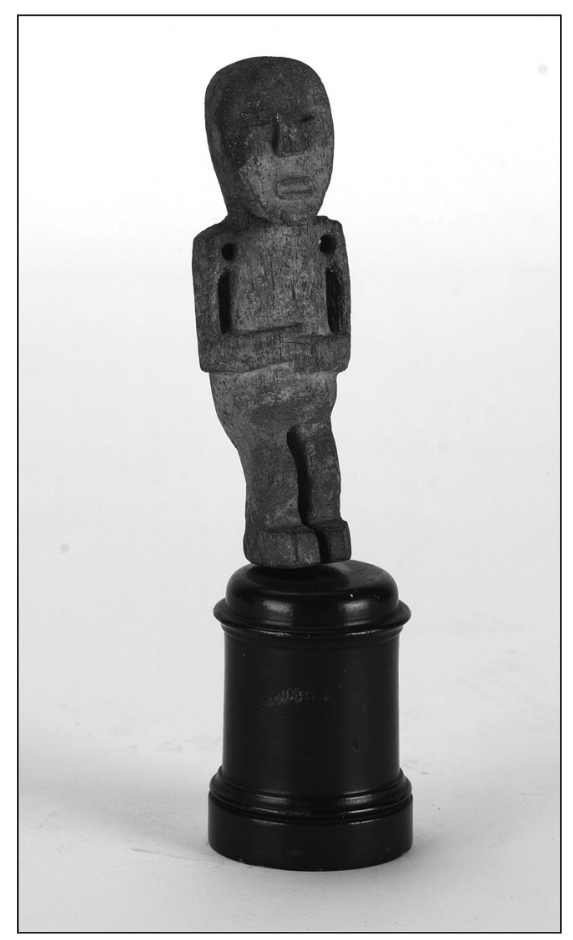

Figura 5. Figurilla femenina parada ( $n^{\circ}$ cat. 36). 


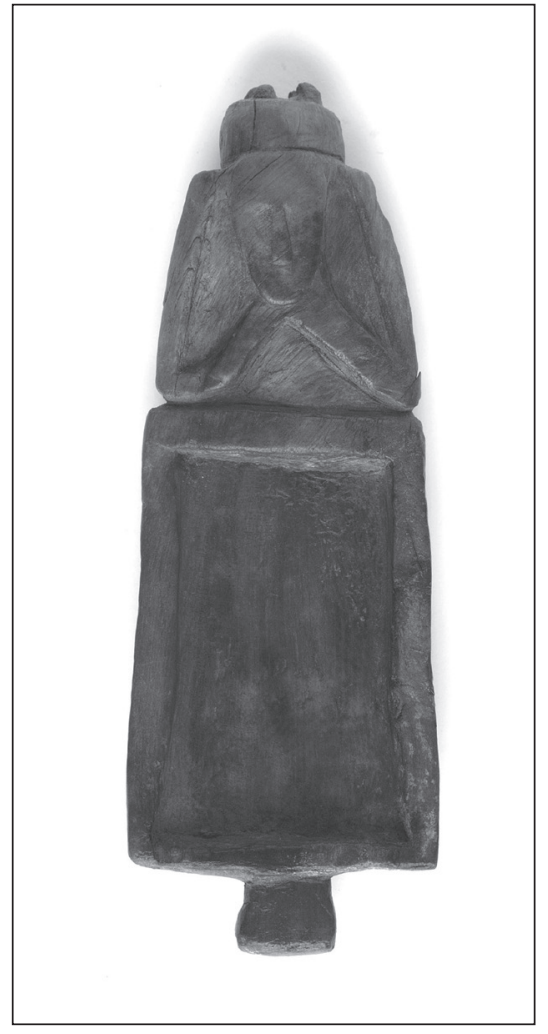

Figura 6. Tableta con personaje masculino ( ${ }^{\circ}$ cat. 36).

parece manifestarse también en dos figuritas humanas desnudas trabajadas a bulto redondo, una que presenta a un hombre parado (Figura $4, n^{\circ}$ cat. 75 ), y otra que representa a una mujer, también parada (Figura $5, n^{\circ}$ cat. 76 ): ambos parecen adelantar, en madera, las figuritas humanas en oro y plata que usarán más tarde los incas, y que probablemente indicaban el hombre, hanan, y la mujer, hurin. En la Colección Campagner podrían indicar que el ritual unía el mundo masculino, hanan, con el mundo femenino, hurin.

Pasemos ahora a la iconografía de los mangos de las seis tabletas, de las dos cucharas y de los tres tubitos. Dichos mangos, por ser medios de comunicación táctil entre la mano de quien los empuña y el ritual, eran un ulterior trámite entre quien los manejaba y el rito chamánico; todo ello nos sugiere que hay que pensar en la iconografía de estos mangos bajo una perspectiva impregnada de un significado simbólico del objeto. Sin embargo, no hay que pasar por alto que, en el ámbito

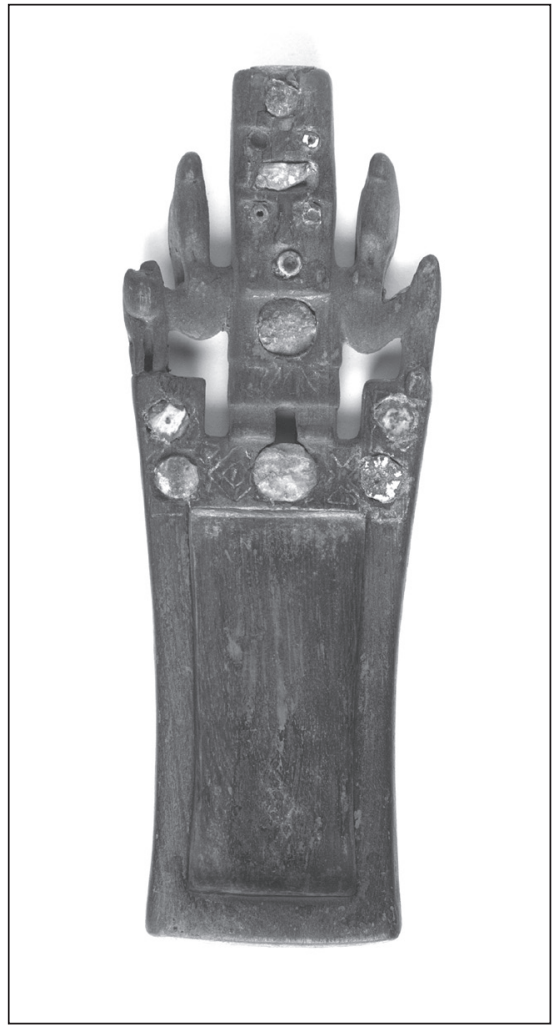

Figura 7. Tableta llamada "del gran sacerdote" (n cat. 43).

del ritual chamánico, las tabletas tienen la función de mesa chamánica puesto que sobre ella el oficiante alinea y arregla sus medios (es decir, la cantidad de polvo de Anadenathera) para realizar luego la visión; por lo tanto, el significado de los mangos sería el de ubicar la mesa chamánica en una posición en la que, formando una unidad con el cuerpo del oficiante, le facilite el ritual. Los mangos de las tabletas están realizados a bulto redondo o en bajorrelieve y, de ellos, tres de las seis tabletas de este artículo ( $\mathrm{n}^{\text {os }}$ de cat. $40,41,38$ ) son a bulto redondo, mientras que las otras tres $\left(n^{\circ s}\right.$ de cat. $36,42,43)$ son en bajorrelieve. Veamos lo que narran: uno (Figura $6, n^{\circ}$ cat. 36 ), parece indicar, al igual que la mayoría de los mangos de tabletas de esta colección, como los señores estaban directamente relacionados con el ritual chamánico: en el caso de la Figura 6, a través de su típico gorro de cuatro puntas hace referencia a Tiwanaku. ${ }^{15}$ Muy interesante en toda la colección por la

${ }^{15}$ En toda la colección atacameña de Mons. Campagner hay siete 


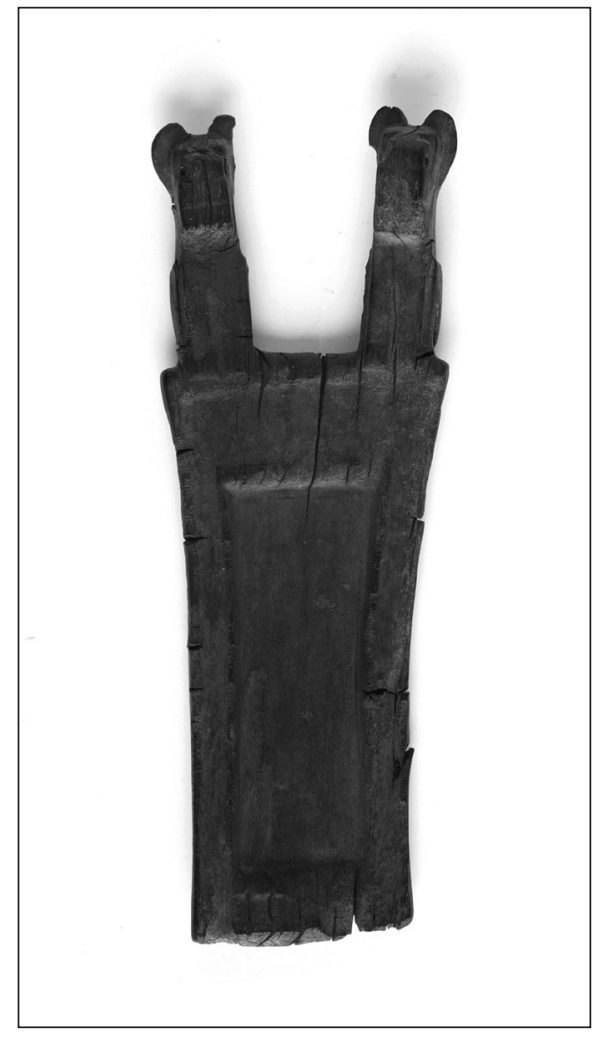

Figura 8. Tableta con pareja de felinos ( $\mathrm{n}^{\circ}$ cat. 41 ).

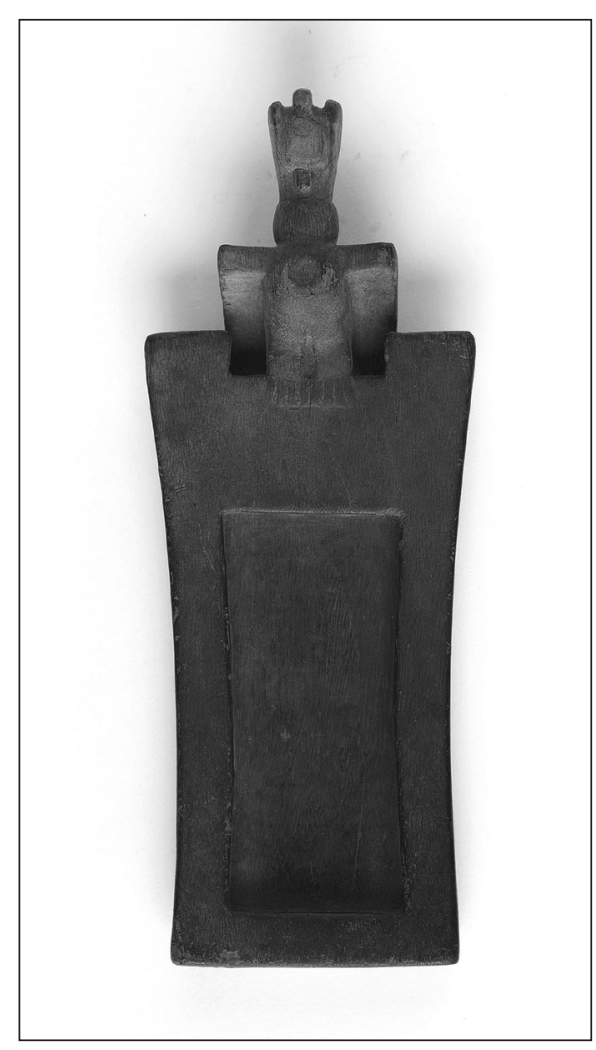

Figura 9. Tableta con ave rapaz (n ${ }^{\circ}$ cat. 38 ). complejidad del trabajo y de la iconografia, es el mango que se puede apreciar en la Figura 7 ( $\mathrm{n}^{\circ}$ cat. 43 ), que retrata un personaje parado sobre un peldaño con gorro cilíndrico; expresa su poder al poner sus manos sobre un felino, casi como para indicar que domina a esos animales, mientras que una pareja de aves rapaces parece velar por él: uno sobre su hombro derecho y el otro

mangos de tabletas que representan personajes importantes $y / 0$ sacerdotes (cuatro de los cuales llevan un gorro de estilo Tiwanaku (n`s 36, 43, 46, 47); uno de ellos, el n 39, lleva un gorro de estilo local; otros dos, los n’s 37 y 44, llevan una máscara de felino con orejas muy grandes que parecen las alas de un murciélago, y el $\mathrm{n}^{\circ} 37$ es además, un sacrificador porque lleva en las manos el hacha y la cabeza trofeo); dos representan a una mujer ( ${ }^{\circ}$ s de cat. 40 , 42 ), dos mangos representan aves rapaces (que pueden aparecer solos, como el $n^{\circ}$ de cat. 38 , o en forma de pareja como el $n^{\circ}$ de cat. 45 ), tres que representan felinos (que pueden estar solos, como aquellos de los n ${ }^{\circ}$ de cat. 48, 49, o formando una pareja, como el del $n^{\circ}$ de cat. 41). Además, hay dos mangos de bandeja que tienen forma de figuras geométricas ( $n^{\circ} \mathrm{s}$ de cat. 50 y 51 ). sobre el izquierdo; felinos y aves rapaces que probablemente son su alter ego o lo que representan. Además, la figura del personaje está engastada con turquesas, de las que hablaremos más adelante: una de forma rectangular está en su frente, una circular en su corazón y cinco más en la plataforma sobre la que se encuentra el personaje. Pareciera que estas dos figuras geométricas trazadas por las turquesas, el rectángulo y el círculo, son los símbolos del personaje y de la geometría del territorio. Se trata probablemente de una divinidad muy importante y/o de su sacerdote. Estos felinos y aves rapaces que, como sugiere también toda la colección, así como la Figura 7, probablemente apoyaban a los chamanes durante la realización del ritual: felinos y aves rapaces aparecen ya sea bajo forma completa de pareja -en cuanto expresa el elemento masculino o hanan y el opuesto, femenino o hurin-, ya sea de manera solitaria. Veamos los ejemplos de los felinos en la Figura 8 ( $\mathrm{n}^{\circ}$ cat. 41 ) que parecen indicar una pareja de pumas que está emprendiendo el "vuelo", como evidencian sus 
orejas bajas señalado que están despegando con el salto, mientras que el ave rapaz de la Figura 9 ( $\mathrm{n}^{\circ}$ cat. 38 ) encaramada sobre la tableta, parece custodiar la mesa del chamán y esperar la orden de volar. Un mango único en la Colección Campagner cuyo estilo es idéntico al mango que se observa en la Figura 7 ( $\mathrm{n}^{\circ}$ cat. 43) y, como esa tableta procede del sitio de Catarpe, es el de la Figura 10 ( $n^{\circ}$ cat. 42 ): representa una mujer en posición generativa (con las piernas abiertas) cuyo tronco forma un rombo cuadrado (con ángulos de 90 grados), cuya cabeza tiene dos grandes ojos circulares y la cabellera está partida por la mitad formando dos culebras, una para cada lado, que están retratadas bajo su forma completa de pareja, y ambas levantando la cabeza. Esta tableta, al igual que la de la Figura 7, está engastada con turquesas para evidenciar las partes más importantes de la imagen: ojos, nariz y una turquesa más grande en forma de cuadrado/rombo en el vientre. Es curioso como esta figura geométrica parece retratada en su forma completa de doble hanan y hurin, por estar la turquesa (clara) del vientre enmarcada en ese rombo de madera cuadrado que forma el tronco: iserá una casualidad o una manera para evidenciar que el rombo cuadrado es el símbolo de la función generativa de la mujer del mango de la bandeja? ¿A quién representa esta mujer? A la luz de las descripciones de la Yaya Mama en el altiplano boliviano, se puede pensar que representa al mismo tiempo a la mama, es decir la tierra antropizada, y a yaya, el padre en forma de culebras que la fecundan. ${ }^{16}$ Además, comparando esta iconografía con las que nos brinda, para los incas, el documento colonial Exsul Immeritus de Valera, se observa que la Pachamama, es decir la tierra antropizada y fecundada quechua, está representada también por el rombo cuadrado, al igual que la mama aymara de la Figura 10, y que la culebra levantando la cabeza simboliza ullu, el poder masculino fecundante, es decir, como el yaya de la Figura 10: este parecido iconográfico nos lleva a aplicar los datos que proporciona Exsul Immeritus sobre los ideogramas a los símbolos de dicha figura, y a una posible ulterior lectura de la misma. Se intuye que el rombo cuadrado podría

\footnotetext{
${ }^{16}$ Yaya Mama (Chávez 2004: 72-73) es el nombre actual de una gran piedra tallada de Taraco, al noreste del lago Titicaca, porque representa una madre (mama) y un padre (yaya). Corresponde a la Pachamama y al miembro masculino ullu que la fecunda. Ver la iconografía y las respectivas explicaciones en Valera (2007 [1618]: Tab. VIII, IX, XI y cc.10v-11r).
}

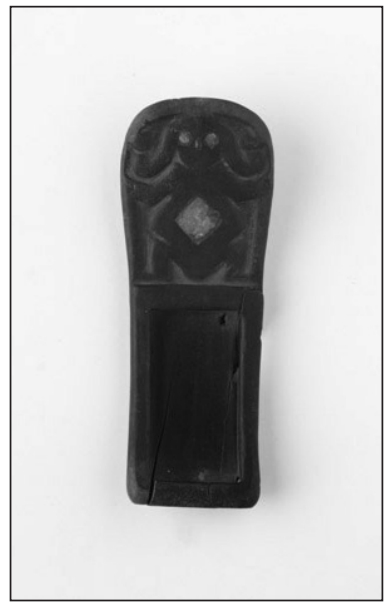

Figura 10. Tableta llamada Yaya Mama (nº cat. 42).

significar también la tierra ordenada por el hombre, la base geométrica para la cuadriculación del territorio de Atacama y su división en las cuatro partes sugeridas, por ejemplo, por la vasija de la Figura 4, mientras que las culebras levantando la cabeza podrían simbolizar también el miembro masculino, el/los ríos que fecundan la tierra así como las mismas culebras (Valera 2007 [1618]; Laurencich-Minelli y Rossi 2007). ${ }^{17}$

Si seguimos con los mangos de las tabletas de la Colección Campagner, hay solo otro mango que probablemente pertenece a una mujer: se trata del mango de la tableta de la Figura 11 ( $n^{\circ}$ cat. 40) que, al limitarse solo a la cabeza, no podemos saber con seguridad si pertenece a una mujer, si bien su cabellera apunta a ello: ital vez se trata de una forma simplificada para simbolizar la Yaya Mama? De todos modos el hecho que la imagen de la mujer y de la Yaya Mama no sea frecuente en la iconografía de los mangos de las tabletas atacameñas de la Colección Campagner, que en cambio proporcionan

\footnotetext{
${ }^{17}$ El rombo/cuadrado para el mundo incaico de acuerdo con el color, representa varios aspectos de huarmi, la mujer: la esposa, la madre, la vagina, mientras que la culebra que levanta la cabeza significa ullu, es decir el miembro masculino, la culebra, el río (Valera 2007 [1618]: Tab. IV, VII, VIIa, VIIIa). Cuadrado que, siguiendo la lógica transformista u holista simboliza en Valera también el Tawantinsuyu y el Inka mismo y la división del mundo en cuatro partes, así como el ábaco o yupana con que se contabilizaba y se cuadriculaba el mundo antropizado (Laurencich-Minelli y Rossi 2007).
} 


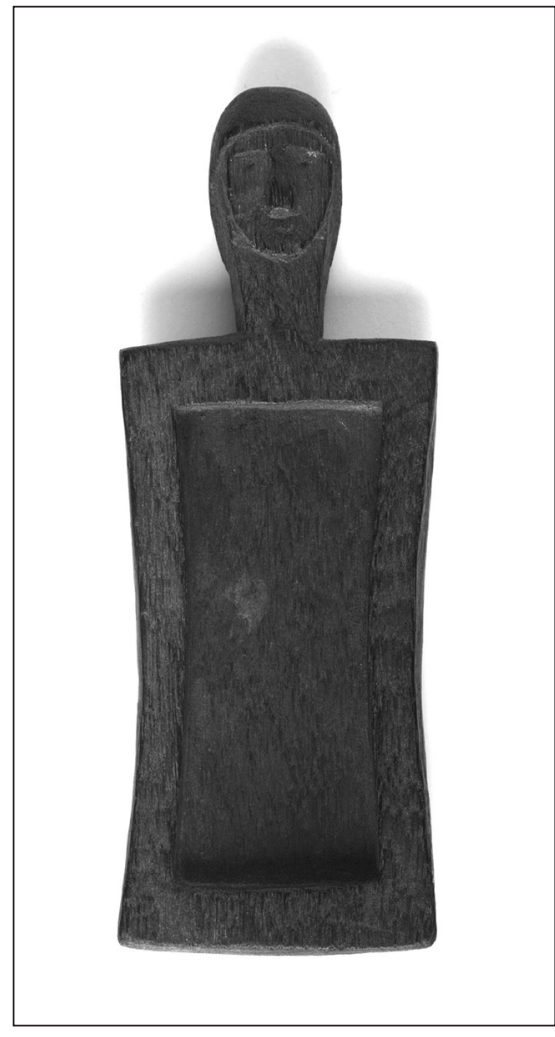

Figura 11. Bandeja con probable cabeza femenina ( ${ }^{\circ}$ cat. 40).

siete figuras masculinas, parece sugerirnos que la mujer era poco importante en esta ceremonia: pero si así fuera, ipor qué en la subárea del Titicaca, con la cual Atacama estaba relacionada durante el período Medio, la Yaya Mama fue en cambio objeto de intenso culto durante un lapso todavía más largo a partir de los tiempos remotos pre-Tiwanaku y se mantuvo, si bien con menor evidencia, hasta Tiwanaku (Chávez 2004)?. De hecho el templo hundido de Tiwanaku, es decir, aquel más antiguo del centro de Kalasasaya (300 AC-400 DC), estaba dedicado al culto de la Yaya Mama y más tarde, en la fase IV (400-800 DC) fue reutilizado, brindando al Monolito Bennett $y$, en la misma época, al conocido como Ponce en el Kalasasaya. Cada uno de estos monolitos creemos que representan un dignatario que sujeta con la mano derecha una tableta cuyos mangos tienen curiosamente forma de cabecita femenina con la cabellera partida en dos al igual que la de la tableta de la Figura 10. Es decir, sujetan una tableta con la Yaya Mama (Berenguer 2001; Couture 2004). De hecho, si miramos exhaustivamen- te al Monolito Ponce, vemos que no sujeta una sola tableta sino dos: una con la mano derecha, cuyo mango es, como se ha dicho, la Yaya Mama, y otra con la mano izquierda cuyo mango es un felino, casi para indicar que en el Kalasasaya, es decir en el corazón del Estado, existían estos dos tipos de tabletas: uno dedicado a la Yaya Mama y el otro al felino. ${ }^{18} \mathrm{Si}$ analizamos estos dos tipos de tabletas del Monolito Ponce y las tabletas de la Figura 10 (la Yaya Mama) y la de la Figura 8 (la pareja de felinos) de la Colección Campagner bajo la óptica del dualismo hanan y hurin, masculino y femenino, que caracteriza al mundo andino, podemos deducir que en Atacama, al igual que en Tiwanaku, había tabletas femeninas (Yaya Mama) y masculinas o del felino. ¿Es tal vez por ser femeninas o hurin, que las tabletas de la Yaya Mama resultan poco frecuentes, como ocurre todavía hoy en día a las mujeres aymara que son también $h u-$ rin y que deben tener menor visibilidad fuera del ayllu que los hombres, a pesar de contar con un poder distinto pero no menor que ellos (Arnold y Yapita 2000)? ¿Tal vez esta tableta pertenece en cambio a una fase en que la Yaya Mama, al igual que la del Monolito Ponce, era objeto de un culto más visible? ¿Tal vez las tabletas tenían la función de personificar la tierra ordenada por el hombre y al mismo tiempo la mesa chamánica al igual que la yupana en la análoga ceremonia inca descrita por Valera (2007 [1618]: cc.9v-11v y Add.II, III), y se quiso evidenciarlo en la tableta de la Figura 10 representando a la Yaya Mama? Por su parte, el mango de las tabletas con felinos es mucho más frecuente en la Colección Campagner. En espera de ulteriores investigaciones estos datos nos permiten por el momento comprobar que las tabletas con felinos aparecen más a menudo entre la parafernalia atacameña de la Colección Campagner que las tabletas con la Yaya Mama.

En lo que concierne a las cucharas de la colección, hay que tener en cuenta que era el oficiante quien las empuñaba en la ceremonia, ya sea para depositar en la tableta el polvo de Anadenanthera, o para provocarse su propio vómito

\footnotetext{
${ }^{18}$ Algunos autores, como Berenguer (2001) y Couture (2004), tal vez por analogía con el Monolito Bennett, sugieren que el Monolito Ponce empuña en la mano derecha una bandeja y en la mano izquierda un kero: interpretación que resulta errónea porque tanto el examen autóptico del objeto como su comparación con el kero presente en el monolito Bennett, señalan que el Monolito Ponce empuña en la mano izquierda una tableta con figura de felino.
} 


$$
11
$$




$$
\frac{11}{11}
$$


Para terminar con esta muestra de 16 objetos de madera utilizados en Atacama para rituales chamánicos, me detengo ulteriormente en las figuras geométricas en que están cortadas las turquesas engastadas en tres tabletas: la de la Figura 10 ( $\mathrm{n}^{\circ}$ cat. 42 , denominado de la Yaya Mama), la de la Figura 7 ( ${ }^{\circ}$ cat. 43 , denominada del Gran Sacerdote) y la tableta $n^{\circ}$ cat. 37. En la primera, las turquesas son circulares y cuadrado/romboidales, en la segunda son circulares y rectangulares, en la tercera, la única turquesa que queda es circular y está colocada entre los dos sacrificadores. ${ }^{22}$ ¿Por qué la elección de turquesas? Sin duda por tratarse de una piedra frecuente en Atacama pero también porque su color tenía un significado mágico-religioso relacionado con el agua corriente y la fertilidad que el agua proporciona a la tierra. Estas turquesas están cortadas en formas geométricas cuadradas, rectangulares y circulares que recuerdan las figuras fundamentales de Tiwanaku, como se aprecia en los grabados de la Puerta del Sol, pero que también forman el trazado urbano de Tiwanaku. Tampoco se debe olvidar

de tablero repartido en casillas, que sería la personificacion de la Pachamama, del mundo hurin, que en el rito tenía la función de la tableta del chamán; 2) los colgantes del quipu utilizado, serían la personificación del felino, esto es de Inti Illapa y también del mundo hanan, colgantes que en el ritual tenían la función biunívoca de conducto a través del cual el amauta comunicaba tanto con el mundo hanan para ubicar el soplo vital que había producido, como recibía el soplo vital que fluía en la tierra del Tawantinsuyu; 3) la bocina que con su sonido marcaba el resultado final del ritual. Haciendo un paralelismo entre los objetos de la parafernalia del ritual atacameño/Tiwanaku y los del ritual inca, es posible que, en el período Medio hallemos las trazas del ritual inca para atrapar el soplo vital, es decir, que el ábaco o yupana sea la transformación inca en clave numérica de la tableta que personificaba la Yaya Mama y que tenía la función de mesa chamánica, los colgantes del quipu serían la transformación del tubito y al mismo tiempo la personificación del dios felino (Inti Illapa en el mundo inca, cuya función de conducto hacía posible la comunicación entre la tableta y el personaje, realizando el ritual de la inhalación de la Anadenanthera).

${ }^{22}$ Los mangos de las demás tabletas de la colección que no describimos en este artículo, están/estaban engastados con turquesas: la bandeja $n^{\circ}$ cat. 37 , que presenta una pareja de Chachapuma, lleva una turquesa circular entre los dos sacrificadores; la bandeja del $n^{\circ}$ cat. 39 que nos deja ver los receptáculos cuadrados, ahora vacíos, estaba engastada en la figura masculina del mango. También las embocaduras de unos tubitos, como el $n^{\circ}$ cat. 61, dejan ver todavía una hilera de cuatro círculos de turquesa con un punto en el fondo de cada uno, es decir, números según Zuidema (1977). que en Chiripa estas figuras geométricas son frecuentes (Chávez 2004). Comparto plenamente la idea de Zuidema (1977) de que las figuras circulares con un círculo o un punto en el fondo, como las que se hallan, por ejemplo, en la tableta de la Figura 7, y los círculos engastados en estos objetos podrían ser números: en el primer caso, el número engastado en la tableta de la Figura 7 , sería el número 2, el de las dos fuerzas opuestas hanan y hurin. ${ }^{23}$ En otras palabras, parece que, en las piezas de la Colección Campagner, las figuras geométricas cortadas en las turquesas escriben el significado de la iconografia mediante símbolos que podrían ser números.

\section{* Palabras finales}

A la espera de ulteriores estudios que comprueben y afinen ya sea el bosquejo cronológico aquí trazado, o bien, la curiosa ideología unificadora, de cuanto se desprende de la Colección Campagner, parece haber unido a la región atacameña con el altiplano del Titicaca, durante el período Medio, termino con unas preguntas que plantea este trabajo y que al mismo tiempo abren posibles líneas de investigación.

La iconografía de los objetos pertenecientes a la parafernalia de la colección atacameña Campagner nos informa, a la espera de ser ampliadas con las de otras colecciones, que el ritual chamánico era un elemento básico de la cultura atacameña durante fines del período Formativo y durante todo el período Medio, así como que la visión que buscaba el chamán estaba relacionada, en la mayoría de los casos, con los Chachapuma, es decir con los "sacrificadores" que capturaban los "enemigos" para conquistar su cabeza y conservarla. ¿Cuál era pues la función de los Chachapuma en el ritual chamánico, puesto que son $\tan$ frecuentes en las ofrendas atacameñas? Sin duda, las excavaciones arqueológicas en Tiwanaku (Kolata 2004: 107-111), al devolvernos varios sacrifica-

\footnotetext{
${ }^{23}$ Para el significado de los números sagrados en el mundo incaico, ver Valera (2007 [1618]: Add. IV), significado que intento aplicar aquí por ser la tradición de la numerología andina persistente, como se puede ver en los textiles y en la cerámica Wari y Tiwanaku, y también en los textiles andinos modernos (Silverman 2008: 152-153, 169, 170, 171). En la Colección Campagner las turquesas circulares con un punto en el fondo se aprecian en las tabletas $n^{\circ}$ s de cat. $43,45,39$ y en el tubito $n^{\circ}$ cat. 61 .
} 
dos degollados, indican que los Chachapuma llevaban a cabo una actividad fundamental en el Estado que era la de capturar cabezas humanas. ¿Cuál era entonces el reto del ritual chamánico en las regiones influenciadas por Tiwanaku? Para hallar una respuesta a estas preguntas nos puede ayudar, por un lado, el ritual de las cabezas trofeos de Amazonia documentado todavía en el s. XX y, por el otro, la comparación con el ritual chamánico en el mundo incaico. Sobre las tsantsas ${ }^{24}$ de Amazonia, a pesar de las diferencias que presentan respecto a las cabezas trofeos Tiwanaku por ser de tamaño inferior, sabemos que permiten, a quien las conquista, capturar una suerte de alianza y el espíritu vital del enemigo. ${ }^{25}$ Tampoco se puede pasar por alto que en la costa sur de Perú existe una larga tradición de cabezas trofeos emplumadas, felinos y sacrificadores que se remonta por lo menos a Paracas Cavernas, ni que en el mundo inca las cabezas de los enemigos capturados en una batalla, tras haberlas reducido a cráneos, se utilizaban como copas, que desde el enfoque europeo de los cronistas se interpretaron como ajuar para celebrar y brindar por la victoria, aunque supongo que tenían también el reto de permitir apoderarse del espíritu del enemigo. ${ }^{26}$ Interesante es lo que cuenta Valera (2007 [1618]) sobre el ritual chamánico en tiempos incaicos tardíos, donde prudentemente nombra al chamán que realizaba el vuelo, amauta, es decir, "sabio", para evitarse posibles condenas por hereje. El estado de trance que él describe se realizaba ya no a través de inhalaciones de Anadenanthera sp. o de otro alucinógeno, sino gracias al canto repetitivo y utilizando la yupana (ábaco) como mesa chamánica, en lugar de la tableta, y los cordeles de los quipu como conductos para comunicar con el mundo hanan, en vez de los tubos inhalatorios. ${ }^{27}$ El reto

\footnotetext{
${ }^{24}$ Tsantsa es como se denomina la cabeza trofeo reducida a la cara y los cabellos que los nativos de Amazonia (p.e., los jíbaros) producían después de haberle quitado el cráneo.

25 Según los jíbaros (Taylor 1985, 1994), el enemigo para el sacrificio sería un enemigo tribal, es decir un "otro" que pertenece a la misma etnia pero consagrado a ser lo que es uno mismo y no un enemigo interno que, en cambio, habría que vengar.

${ }^{26}$ Para Paracas Cavernas, ver la iconografía textil, en que ya sea un felino devorando cabezas humanas emplumadas, ya sea un ser humano (iun sacrificador?) que sujeta dos cabezas trofeos y tiene otras en su vientre y en la extremidad de sus cabellos (Kauffmann-Doig 1993: 251). Para la cultura inca ver Rowe (1946: 279).

${ }^{27}$ De acuerdo con Valera (2007 [1618]) el canto repetitivo marcaba el recorrido del amauta entre los varios dioses "escritos" iconográficamente en unos cantos específicos después de haberlos
}

del ritual chamánico incaico descrito por Blas Valera es capturar del aliento vital que corre peligrosamente desencadenado por todo el cielo y fijarlo en las huaca de la tierra, la Pachamama, de manera que sea benéfico para los hombres. En la hipótesis de aplicar al ritual chamánico atacameño/Tiwanaku el reto del ritual chamánico inca, ¿cuál sería la función de los Chachapuma en la visión? Sería la de procurarse el aliento vital del enemigo de manera que el chamán lograra transferirlo a las huaca ordenadas de la Yaya Mama. Aliento vital que probablemente es el mismo del Camac (G. Taylor 2000) y, tal vez de aquel "ser monstruoso" que domina el mundo Nazca y que aparece retratado en tejidos y vasijas mientras vuela amenazador. De acuerdo con nuestra interpretación de esta porción de la Colección Campagner, en esta función de captar y ordenar el aliento vital, el Chachapuma y la nobleza a la cual pertenece, actuaría como chamán ayudado por sus alter ego, el felino, que es también el alter ego preferido del mismo Chachapuma, y que lo representa, y el ave rapaz que tal vez encarnaría las cabezas trofeos. ${ }^{28}$

Otra hipótesis de trabajo digna de investigación es la que plantea unas piezas de la Colección Campagner que parecen expresar adelantos de ciertos elementos incas. Es decir, ¿son rasgos de la concepción básica del Tawantinsuyu la división en cuatro de la vasija de la Figura 3 y las figurillas masculinas y femeninas desnudas y paradas de las Figuras 4 y 5 ? Sin embargo, éstas, y la tableta de la

trasformado en números para luego calcularlos, con curiosos cálculos holísticos, sobre el ábaco o yupana, con el fin de obtener el supuesto número que corresponde a la divinidad y de fijarlos sobre el quipu para dejar constancia del recorrido "numérico" que había hecho para alcanzar esa divinidad, que era la que permitía el rito del vuelo chamánico que consistía en: 1) tener la visión de la cantidad de aliento vital (el cronista llama, en latín: vitalis spiritu) que él había logrado suscitar en el mundo hanan con sus curiosas cuentas de los números/dioses: vitalis spiritu que, abandonado a sí mismo, podía ser peligroso para los hombres por su capacidad de correr desordenadamente en el mundo hanan y así producir el amaru tan destructivo; 2) siguiendo su estado de trance, el amauta sin dejar de cantar tenía que capturar este aliento vital para fijarlo, bien ordenado, en las huaca de la tierra, esto es en el hurin de la Pachamama, donde transformarlo en soplo benéfico para la humanidad (Laurencich-Minelli 2004b, 2007a, 2007b).

${ }^{28}$ Que el ave rapaz personifique las cabezas trofeos lo sugieren las cabezas trofeos Nazca que por lo general están retratadas entre las plumas de rapaz del Ser Monstruoso (Kauffmann-Doig 1993: Figuras 152, 158, 159, 165). 
Figura 10 (con la Yaya Mama), nos llevarían a confirmar la observación de Meyers (2002: 532), quien, de acuerdo con datos arqueológicos, sostiene que toda el área nuclear de Tiwanaku fue la zona inicial incaica y que los incas ganaron su poder no militarmente, sino reformando lo trascendente de Tiwanaku. Es decir, reformaron "el concepto ctónico orientado hacia la tierra" (la Yaya Mama de la Figura 10 que corresponde a la Pachamama) con "una proyección hacia arriba" que personalizaron con figuras del mundo inca, como sus coyas y sus momias. Las observaciones arqueológicas de Meyers quedarían curiosamente confirmadas, en su aspecto etnohistórico, por el manuscrito Exsul Immeritus de Valera, que no solo considera que la cultura inca empezaría al final del período Medio sino que evidencia también como el culto ctónico de la Pachamama de los primeros tiempos de los incas fue sustituido por el culto de la ñusta por uno de los primeros incas, el mítico Inka Mayta Capac. ${ }^{29}$

Agradecimientos A Albert Meyers de la Universidad de Bonn por su discusión sobre los rasgos de cultura incaica en Tiwanaku; a Yolanda Sabaté, Universidad de Bolonia y a Carolina Agüero de la Universidad Católica del Norte, por la revisión respectivamente de la lengua española y de la terminología técnica.

\footnotetext{
${ }^{29}$ El culto ctónico de Pachamama de los primeros tiempos de los incas fue substituido por el culto a la ñusta, es decir por un culto celeste, hasta el punto que Valera (2007 [1618]: c.9v) refiere que el cuarto Inka mítico, Mayta Capac, sustituyó el canto Pachacamac por el canto Sumac Nusta donde la ñusta cubre la función de la Pachamama. Ver también Laurencich-Minelli (2007a) y Bongiorno (2007).
}

\section{* Referencias citadas}

ARNOLD, D. y J. YAPITA, 2000. El rincón de las cabezas. Luchas textuales, educación y tierras en los Andes. Colección Academia 9 , La Paz.

BAUER, B., 1996. The legitimization of the Inca State in myth and ritual. American Anthropologist 98 (2):327-337.

BERENGUER, J., 2001. Evidence for snuffing and shamanism in prehispanic Tiwanaku stone sculpture. Eleusis 5: 61-83.

BERENGUER, J., A. DEZA, A. ROMÁN y A. LLAGOSTERA, 1986. La secuencia de Myriam Tarrago para San Pedro de Atacama: Un test por termoluminiscencia. Revista Chilena de Antropología $5:$ 17-24.

BERENGUER, J., A. ROMÁN, A. DEZA y A. LLAGOSTERA, 1988. Testing a cultural sequence for the Atacama Desert. Current Anthropology 29 (2): 341-46.

BITTMANN, B., G. LE PAIGE y L. NÚÑEZ, 1978. Cultura atacameña. Departamento de Extensión Cultural del Ministerio de Educación, Santiago.

BONGIORNO, V., 2007. Nomi di re Inca nel testo seicentesco Exsul Immeritus Blas Valera Populo Suo, Per bocca d' altri: Inca, gesuiti e spagnoli nel Perù del XVII secolo. Tavola rotonda sui doc. Miccinelli, Alma Digital Library, Università di Bologna, L. Laurencich Minelli y D. Domenici (Eds.), pp. 159-185. http://almadl.cib. unibo.it
BOZZOLI, M. E., 1982 Ms. Especialistas en la medicina aborigen Bribri. Informe preliminar. Departamento de Antropología, Universidad de Costa Rica, Costa Rica.

BURGER, R., 1993. Emergencia de la civilización en los Andes: Ensayos e interpretación. Universidad Nacional Mayor de San Marcos, Lima.

CAMPAGNER, A., 1965. Collezione archeologica precolombiana di Monsignor Angelo Campagner. Catalogo a cura del Liceo scientifico Leonardo da Vinci, Treviso.

1993. Archeologia e paletnografia precolombiana del Sudamerica. La raccolta nel Seminario vescovile di Treviso. Tipografia Editrice Trevigiana, Treviso.

CARRIÓN, R., 1959. La religión en el antiguo Perú. Tipografía peruana, Lima.

CHÁVEZ, J., 2004. The Yaya Mama religious tradition as an antecedent of Tiwanaku. En Tiwanaku ancestors of the Inca, M. YoungSánchez (Ed.), pp. 70-95. Denver Art Museum, University of Nebraska Press, Lincoln y Londres.

COBO, B., 1956 [1653]. Historia del Nuevo Mundo. Biblioteca de Autores Españoles, Madrid.

DESVEAUX, E., 2001. Quadratura americana. Essai d' antropologie lévi-straussienne. Georg, Collection Ethnos, Genova. 
FRAME, M., 1986. The visual images of fabric structures in Ancient Peruvian art. En The Jiunius Bird Conference of Andean Textiles, A. Rowe (Ed.), pp. 47-8o. The Textile Museum, Washington D.C.

2004. Motion pictures: Symmetry as animator. Classifier and syntax in the Nasca embroideries of Peru. En Symmetry comes of age: The role of pattern in culture, D. Washburn y D. Crowe (Eds.), pp. 133-176. University of Washington Press, Washington D.C.

\section{KAUFFMANN-DOIG, F., 1993. Peru-Inca. Erizzo, Venecia.}

KOLATA, A., 2004. The flow of cosmic power: Religion, ritual and the people of Tiwanaku. En Tiwanaku ancestors of the Inca, M. Young-Sanchez (Ed.), pp. 96-113. Denver Art Museum, University of Nebraska Press, Lincoln y Londres.

LAURENCICH-MINELLI, L., 2003a, El curioso concepto de "cero concreto" mesoamericano y andino y la lógica de los dioses. Números incas: Una nota. "Especulo" 27, Revista de la Universidad Complutense. http://www.ucm.es/info/especulo/numero27/cero. html. 2004.

2003b. Una nota su ulteriori possibilità di lettura del calendario rituale del Codice Cospi. Atti del Colloquio Internazionale $l$ Sacro e il paesaggio nell America Indigena, D. Domenici, C. Orsini y S. Venturoli (Eds.), pp. 101-114. Università di Bologna, Bologna.

2004. Quipu y escritura en las fuentes jesuíticas en el virreinato del Perú entre el final del s. XVI y la primera mitad del s. XVII: En El Silencio protagonista. El primer siglo jesuita en el Virreinato del Perú. 1567-1667. Actas del $51^{\circ}$ Congreso Internacional de Americanistas, pp. 171-212. Abya Yala, Quito.

2006. La yupana: Abaco e ordinatore dello spazio inca o esempio di sincretismo culturale? Acta del XXVIII Convegno Internazionale diAmericanistica, pp. 313-326. Mérida.

2007a. La curiosa serie degli Inca di Exsul immeritus Blas Valera Populo Suo. Per bocca d' altri: Inca, gesuiti e spagnoli nel Perù del XVII secolo. Actas Tavola rotonda sui doc. Miccinelli, L. Laurencich-Minelli y D. Domenici (Eds.), pp. 105-158. Alma Digital Library, Università di Bologna. http://almadl. cib.unibo.it.

2007b. Exsul Immeritus Blas Valera Populo Suo e Historia et Rudimenta Linguae Piruanorum. CLUEB, Bologna.

LAURENCICH-MINELLI, L. y M. COLELLA, 2008. La collezione precolombiana Campagner, vol. 1. Treviso, Tip., Tintoretto.

LAURENCICH-MINELLI, L. y E. ROSSI, 2007. La yupana de la Nueva Corónica y las yupanas de Exsul Immeritus Blas Valera
Populo Suo: ¿Ábaco y escritura Inca o sincretismo jesuita? En Sublevando el Virreinato. Documentos contestatarios a la historiográfica tradicional del Perú Colonial, L. Laurencich Minelli y P. Numhauser (Eds.), pp. 375-423. Abya Yala, Quito.

LE PAIGE, G., 1964. El precerámico en la cordillera atacameña y los cementerios del período Agroalfarero de San Pedro de Atacama. Anales de la Universidad del Norte 3.

LÓPEZ, A., 1983. Nota sobre la fusión y la fisión de los dioses en el panteón méxica. Anales de Antropología XX (2): 75-87.

1997. La religione della Mesoamerica. En Storia delle Religioni, vol. 5, G. Filoramo (Ed.), p. 55. Bari, Roma.

MEYERS, A., 2002. Los incas: ¿Bárbaros advenedizos o herederos de Tiahuanaco? En El hombre y los Andes: Homenaje a Franklin Pease, vol. 2, J. Flores Ochoa y G. Varón (Eds.), pp. 525-535. Pontificia Universidad Católica del Perú, Fondo Editorial, Lima.

OAKLAND, A., 1992. Textiles and ethnicity: Tiwanaku in San Pedro de Atacama, North Chile. Latin American Antiquity (3) 4: 316-340.

PONCE, C., 1972. Tiwanaku: Espacio, tiempo y cultura. La Paz.

POSNANSKY, A., 1945. Tihuanacu, la cuna del hombre americano. J. J. Augustin Publisher, Nueva York.

RAMOS GAVILÁN, A., 1988 [1621]. Historia del célebre Santuario de Ntra. Sra. de Copacabana e invención de la Cruz de Carabuco. Edición Ignacio Prado R, Lima.

ROWE, J. H., 1946. Inca culture at the time of the Spanish Conquest. En The Andean Civilization, Handbook of South American Indians, vol. 2, J. Steward (Ed.), pp. 183-330. Bureau of American Ethnology, Smithsonian Institution, Bullettin 143, Washington D.C.

SILVERMAN, G., 2008. A woven book of knowledge. Textile iconography of Cuzco, Peru. University of Utah Press, Salt Lake City.

TARRAGÓ, M., 1968. Secuencias culturales de la etapa agroalfarera de San Pedro de Atacama (Chile). Actas y memorias del XXXVII Congreso Internacional de Americanistas, vol. 2, pp. 119-145. Buenos Aires.

1989. Contribución al conocimiento arqueológico de las poblaciones de los oasis de San Pedro de Atacama en relación con los otros pueblos puneños, en especial, el sector septentrional del valle Calchaquí. Tesis doctoral de Historia. Universidad Nacional de Rosario, Facultad de Humanidades y Artes, Rosario. 


\section{Laura LaUrencich-Minelli}

TAYLOR, A., 1985, L'art de la reduction: La guèrre et les mécanismes de la différenciation tribale dans les jivaro. Journal de la Societédes Américanistes 71: 159-173.

1994. Les bons ennemis et les mauvais parents: Les treitement sumbolique de l'alliance dans les rituels de chasse aux têtes des shuar (jivaro) de l' Equateur. Les stratégies de l'alliance matrimoniale. Archives Contemporaines IV: 73-105.

TAYLOR, G., 2000. Camac, camay y camasca y otros ensayos sobre Huarochiríy Yauyos. Instituto Francés de Estudios Andinos, Lima.

TORRES, C. M., 2004, Tiwanaku snuffing paraphernalia. En Tiwanaku ancestors of the Inca, M. Young-Sanchez (Ed.), pp. 114-125. Denver Art Museum, University of Nebraska Press, Lincoln y Londres.

UHLE, M., 1919. Arqueología de Arica y Tacna. Boletín de la Sociedad Ecuatoriana de Estudios Históricos Americanos 7-8, Quito.
1922. Fundamentos étnicos y arqueología de Arica y Tacna. Imprenta de la Universidad Central, Quito.

VALCÁRCEL, L., 1925. Del ayllu al Imperio. Editorial Garcilaso, Lima.

1965 [1945]. Ruta cultural de Perú. Ediciones Nuevo Mundo, Lima.

VALERA, B., 2007 [1618]. Exsul Immeritus Blas Valera Populo Suo. L. Laurencich-Minelli (Ed.). CLUEB, Boloña.

WASSÉN, H., 1972. A medicin man's implements and plants in a Tiahuanacoid tomb in Highland Bolivia. Etnologiska Studier 32, Gotemburgo.

ZUIDEMA, T., 1977. The inca calendar. En Native American astronomy, A. Aveni (Ed.), pp. 219-259. University of Texas Press, Austin. 